Nova Southeastern University

Florida

NOVA SOUTHEASTERN

UNIVERSTYY

NSUWorks

Marine \& Environmental Sciences Faculty Articles Department of Marine and Environmental Sciences

10-1-2009

\title{
Relationship of Reef Fish Assemblages and Topographic Complexity on Southeastern Florida Coral Reef Habitats
}

Brian K. Walker

Nova Southeastern University, walkerb@nova.edu

Lance K. B. Jordan

Nova Southeastern University

Richard E. Spieler

Nova Southeastern University, spielerr@nova.edu

Find out more information about Nova Southeastern University and the Halmos College of Natural Sciences and Oceanography.

Follow this and additional works at: https://nsuworks.nova.edu/occ_facarticles

Part of the Marine Biology Commons, and the Oceanography and Atmospheric Sciences and Meteorology Commons

\section{NSUWorks Citation}

Brian K. Walker, Lance K. B. Jordan, and Richard E. Spieler. 2009. Relationship of Reef Fish Assemblages and Topographic Complexity on Southeastern Florida Coral Reef Habitats Journal of Coastal Research, (Special Issue 53) : 39 -48.

https://nsuworks.nova.edu/occ_facarticles/134.

This Article is brought to you for free and open access by the Department of Marine and Environmental Sciences at NSUWorks. It has been accepted for inclusion in Marine \& Environmental Sciences Faculty Articles by an authorized administrator of NSUWorks. For more information, please contact nsuworks@nova.edu. 


\begin{tabular}{|c|c|c|c|c|c|}
\hline Journal of Coastal Research & SI & 53 & $39-48$ & West Palm Beach, Florida & Fall 2009 \\
\hline
\end{tabular}

\title{
Relationship of Reef Fish Assemblages and Topographic Complexity on Southeastern Florida Coral Reef Habitats
}

\author{
Brian K. Walker*, Lance K.B. Jordan, and Richard E. Spieler
}

Nova Southeastern University

Oceanographic Center

National Coral Reef Institute

8000 North Ocean Drive

Dania Beach, FL 33004

*walkerb@nova.edu

\begin{abstract}
Walker, B.K.; Jordan, L.K.B., and Spieler, R.E., 2009. Relationship of reef fish assemblages and topographic complexity on southeastern Florida coral reef habitats. Journal of Coastal Research, SI(53), 39-48.
\end{abstract}

Reef fish assemblage relationships with in situ and lidar topographic measurements across the seascape were analyzed to evaluate the possibility of using lidar metrics as a proxy for prediction models. In situ topographic complexity (i.e., linear rugosity) was measured from 346 point-count fish surveys spanning the reef seascape. Lidar topographic measurements (i.e., surface rugosity, elevation, and volume) were obtained from a high-resolution lidar bathymetric dataset of each survey's footprint. The survey sites were characterized by an independently derived benthic habitat map. Reef fish abundance and species richness appeared to increase with increasing topographic complexity. Although significant, the relationship was weak. Habitat characterization showed that these relationships changed across the seascape. The relationship between topographic complexity and species richness was more pronounced in shallow habitats, whereas, topographic complexity related more closely to abundance in offshore habitats. In situ rugosity measurement yielded the best explanation of fish assemblage structure parameters, but the weaker lidar metric correlations followed similar trends. Accordingly, lidar-measured topographic complexity may be a useful metric for reef fish distributional models. Such predictive models could have many scientific and management applications including: estimating fish stocks, viewing data trends across the seascape, and designing marine protected areas. However, better understanding of the appropriate spatial scale, measurement scale, and fish operational scale is needed, as well as more research on the dynamics of how reef fishes relate to topographic complexity and other ecological factors influencing distributions across the seascape.

ADDITIONAL INDEX WORDS: Seascape ecologv, habitat complexity, rugosity, coral reef fish, lidar, GIS

\section{INTRODUCTION}

A fundamental principle in ecology assumes abiotic and biotic variables influence the distribution of all organisms, including marine fishes (Putman and Wratten, 1984; Recksiek et al., 2001). Abiotic variables such as temperature, salinity, depth, current, and topographic complexity, and ecological processes including recruitment, competition, food availability, and predation all play roles in determining fish species distribution and abundance (Sale, 1991a and $1991 \mathrm{~b}$ ). Where temperature and salinity are relatively consistent, other variables can impact associated fish assemblages, including the physical arrangement of the seafloor, often measured as topographic complexity or rugosity (Appeldoorn et al., 1997; Bell, McCoy, and Mushinsky 1991; Chabanet et al., 1997; Friedlander et al., 2003; Friedlander and Parrish, 1998; Garcia Charton and Perez Ruzafa, 1998; Gratwicke and Speight, 2005a and 2005b; Hixon and Beets, 1989; Jordan, Gilliam, and Spieler, 2005; Luckhurst and Luckhurst, 1978; McClanahan, 1994; McCoy and Bell, 1991). Topographic complexity has been linked to increased species diversity in many ecological communities (Johnson et al., 2003; MacArthur and MacArthur, 1961; Petren and Case, 1998) including fishes on coral reefs. Many studies have also found positive relationships between

DOI: $10.2112 /$ SI53-005.1 topographic complexity and reef fish abundance, biomass, and/or species richness (Appeldoorn et al., 1997; Friedlander et al., 2003; Friedlander and Parrish, 1998; Gratwicke and Speight, 2005a and 2005b; Green, 1996; Kuffner et al., 2007; Luckhurst and Luckhurst, 1978; McClanahan, 1994; McCormick, 1994; Risk, 1972; Talbot, 1965; Talbot and Goldman, 1972).

In situ reef topographic complexity can be measured in several ways (Brock et al., 2004; McCormick, 1994; Risk, 1972; Underwood and Chapman, 1989). The most frequently used method is a measurement of reef surface complexity known as rugosity. Rugosity is most commonly measured by the chain-and-tape method (McCormick, 1994), whereby a ratio of the length of a chain draped across the reef surface to the linear stretched length is calculated (Hobson, 1972; Risk, 1972; Talbot and Goldman, 1972). This ratio, hereafter referred to as linear rugosity, provides a rugosity measurement (index) that has been used to examine its relationship with fish abundance, biomass, species richness, and species diversity indices.

Remote sensing allows for the characterization of broad areas of the seafloor by visual interpretation of imagery and high resolution Light Detection and Ranging (lidar) bathymetry (Walker, Riegl, and Dodge, 2008). Lidar bathymetry also allows for the calculation of seafloor topography metrics at multiple spatial scales in GIS (Kuffner et al., 2007; Pittman et al., 2007; Pittman, Costa, and Battista, 2009; Purkis, Graham, and Riegl, 2008). These metrics 
include: minimum and maximum depth, elevation, surface-rugosity index, and volume within a given area. If relationships between lidar topographical metrics and reef fish assemblage metrics can be quantified and correlated, then predictions about the assemblages can be made across the seascape based on seafloor topography and benthic habitat associations (Pittman et al., 2007; Pittman, Costa, and Battista, 2009; Walker, 2008).

We investigated the relationship between reef fish assemblage attributes and topographic complexity metrics on coral reef habitats in southeast Florida. Statistical analyses of reef fish abundance and species richness were conducted to elucidate their relationship to in situ rugosity (i.e., linear rugosity) and lidar topographic measurements (i.e., elevation, surface rugosity, and volume) across multiple reef habitats to evaluate the possibility of using these metrics as inputs for predictive models.

\section{METHODS}

\section{Visual Fish Assessments}

Fish data were collected as part of a quantitative effort to acquire a baseline census of coral reef-associated fishes in Broward County, Florida (Ferro, Jordan, and Spieler, 2005). Between 1998 and 2002, Ferro, Jordan, and Spieler (2005) conducted GPS-located pointcount fish surveys using the Bohnsack and Bannerot (1986) method throughout the reef system of Broward County, FL, USA. Our study used a subset of 346 surveys from Ferro, Jordan, and Spieler (2005) conducted between 2000 and 2002 along 54 cross-shelf transects, each separated by approximately $0.5 \mathrm{~km}$, spanning $24.5 \mathrm{~km}$ along Broward County's reef tract from Port Everglades to the northern county line (Figure 1). Most transects consisted of nine point-count surveys targeting the eastern edge, crest, and western edge of each of the three main reef tracts (Figure 2).

Prior to each fish survey, a $7.5-\mathrm{m}$ line was extended from the survey center, across the area of highest rugosity as visually determined by the diver. Upon completion of the fish census, a fiberglass measuring tape was used to measure the distance of the reef surface along the $7.5 \mathrm{~m}$ linear distance, following all the contours of the reef. A linearrugosity index was calculated by dividing the contour distance by the linear distance. A differential GPS coordinate was taken from the boat at the end of each survey.

A quality-control analysis was performed in a geographic information system (GIS) to filter out sites with inconsistent spatial information. The site coordinates were imported into ArcGIS 9.2, overlaid onto a hill-shaded bathymetry layer and compared with the in situ diver estimates of depth, elevation, and proximity to the reef edge. If the lidar topography around the GPS coordinate did not agree with the diver's site description or was not within 1-m depth of in situ-recorded depth, that site was discarded from analysis. Fish surveys in benthic habitats with fewer than 25 samples were also removed from analyses to avoid errors associated with low replication. Eighty-one surveys were discarded during the qualitycontrol analysis leaving a total of 346 surveys for the topographic analyses.

\section{Bathymetric Survey}

A lidar bathymetric survey was conducted during April 2001 by Tenix LADS Corporation of Australia, using the Laser Airborne Depth Sounder (LADS) system with a sounding rate of $900 \mathrm{~Hz}$

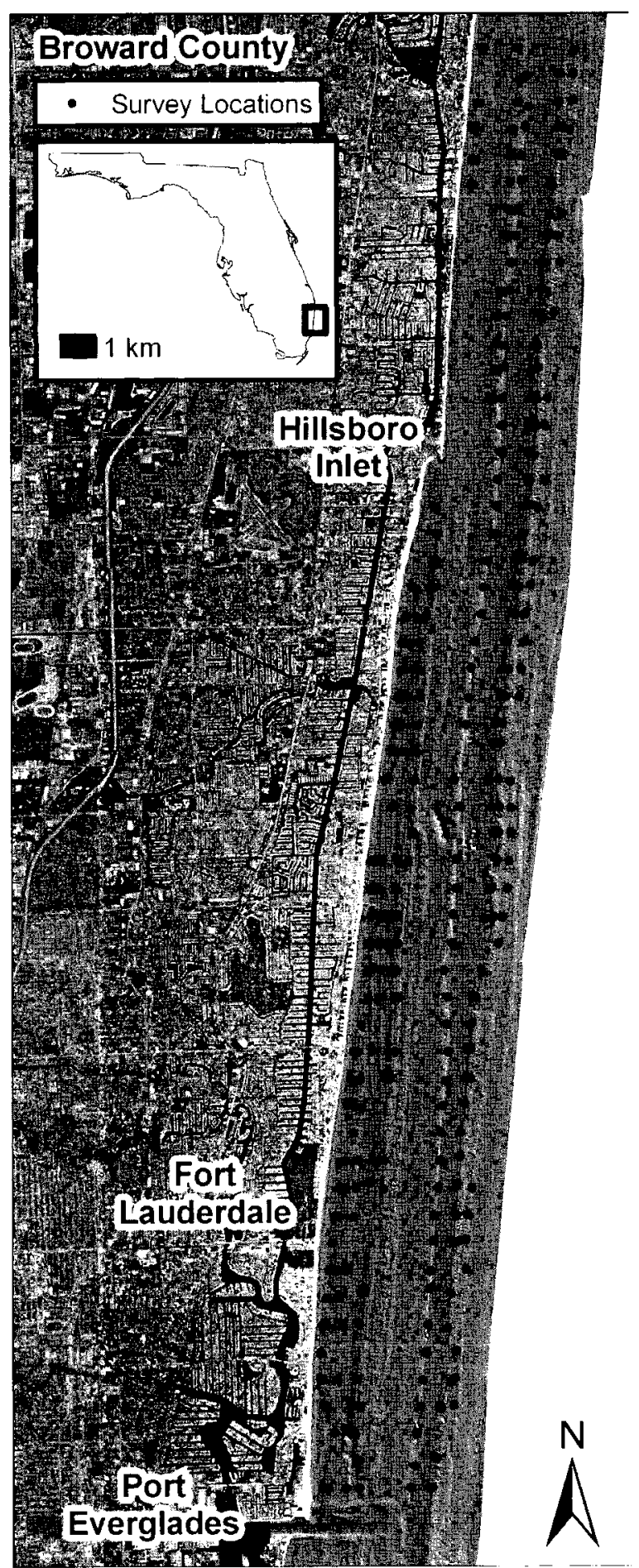

Figure 1. Aerial photo-lidar mosaic with 346 point-count fish assessment sites along 54 cross-shelf transects in northern Broward County. Transects were placed on east-west parallels every 0.250 minutes (approximately every 0.5 $\mathrm{km})$. 


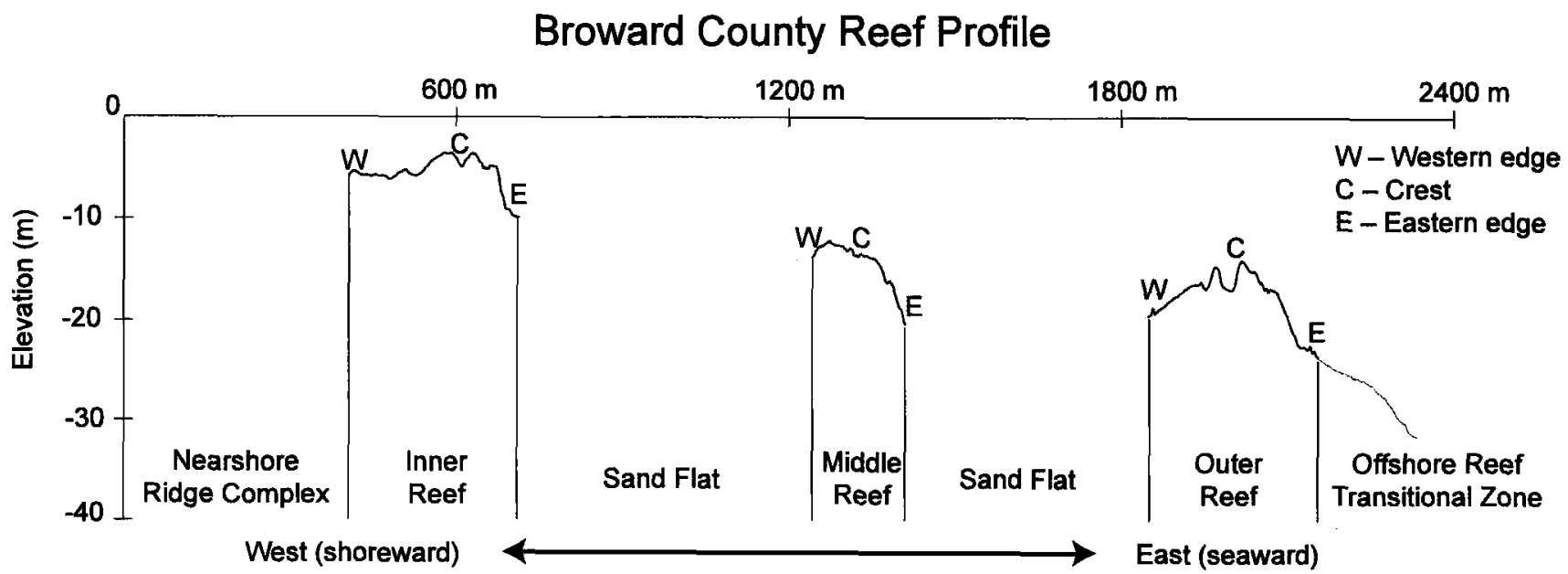

Figure 2. Seafloor reef profile taken from an east-west transect of LADS bathymetry data from $0 \mathrm{~m}$ to $-30 \mathrm{~m}$ off central Broward County, FL. X-axis represents distance from shore and $y$-axis represents elevation. The dark line along the profile represents the three main shore-parallel reef tracts. The letters above the profile indicate the nine areas targeted along each transect for the point-count fish surveys. $E=$ east; $C=c r e s t ; ~ W=$ west.

(3.24 million soundings per hour), a position accuracy of $95 \%$ at 5-m circular error probable, a horizontal sounding density of $4 \mathrm{~m}$ x $4 \mathrm{~m}$, a swath width of $240 \mathrm{~m}$, area coverage of $64 \mathrm{~km}^{2} / \mathrm{hr}$, and a depth range of $70 \mathrm{~m}$, depending on water clarity. The entire survey area covered approximately $110 \mathrm{~km}^{2}$ including the area in which all fish surveys were conducted (see Banks et al., 2007; Finkl, Benedet, and Andrews, 2005, and Walker, Riegl, and Dodge, 2008, for more information on the bathymetric survey).

\section{3-Dimensional Lidar Analyses}

The 3-dimensional lidar analyses were performed using ArcGIS 9.2 with the 3D Analyst, Spatial Analyst, and Geostatistical Analyst extensions. High-resolution bathymetry points from the lidar survey were imported into ArcGIS as XYZ data. A triangulated irregular network (TIN) was created from the points to generate a 3D surface. The TIN of the lidar survey area was clipped to a $7.5-\mathrm{m}$ radius buffer around each of the DGPS-located visual fish survey sites, converted to feature data, and converted back to individual TINs for each survey site (Figure 3 ). The individual TINs were then analyzed in 3D Analyst for $Z$ min, $Z$ max, 2D area, 3D surface area, and volume. The depth of each survey was calculated as the minimum $Z$ value ( $\mathrm{Z}$ min) within the individual TNN. Elevation within an individual survey was the absolute value of the difference between $\mathrm{Z}$ min and $\mathrm{Z}$ max. The $2 \mathrm{D}$ planar area was the area within the $7.5 \mathrm{~m}$ buffer $\left(176.71 \mathrm{~m}^{2}\right)$. The 3D surface area was the area of each triangle in the TIN along its slope to account for the variations in height of the 3D surface. The surface-rugosity index was calculated by dividing the $3 \mathrm{D}$ surface area by the $2 \mathrm{D}$ planar area. Volume was the space between the $3 \mathrm{D}$ surface and a horizontal plane located at the $\mathrm{Z}$ min value.

TINs were used to calculate topographic statistics because vector data are more precise and accurate than raster-based calculations, especially in cases with low data resolution (Wang and Lo, 1999; Jenness, 2004). TINs utilize the original data points as their vertices (Petrie, 1990) and the vector-based format more precisely models the edges of the data (Jenness, 2004). Raster data contains rough edges on diagonals and arcs due to its pixel-based format (Jenness, 2004) and interpolation methods can be subjective. Other recent studies relating lidar bathymetry and fish assemblages have used a pixelbased topographic analysis due to the ease and speed of calculation (Kuffner et al., 2007; Pittman et al., 2007; Pittman, Costa, and Battista, 2009; Purkis, Graham, and Riegl, 2008). It is unknown if different interpolation methods would measurably change their results, but the greatest difference detected by Jenness (2004) when comparing TIN and raster-based topographic calculations was $4 \%$.

\section{Seascape Characterization}

Visual interpretation of a hillshaded lidar bathymetric surface, supplemented by acoustic ground discrimination, aerial

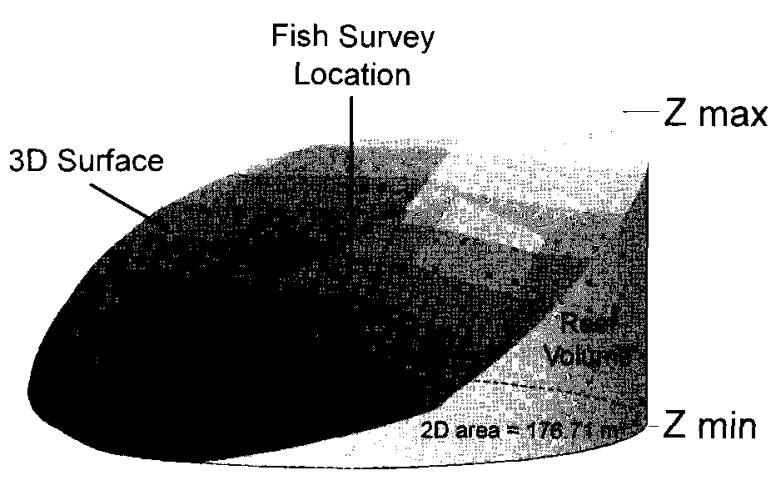

Figure 3. Lidar metrics from analysis of a surface layer. Elevation $=$ minimum $Z$ minus maximum $Z$; Volume = space under the surface to the minimum $Z$ min; Surface-rugosity index $=3 \mathrm{D}$ surface area divided by planar area. 
Table 1. Hierarchical classification scheme showing the benthic habitats nested in the three reef categories (Walker, Riegl, and Dodge, 2008).

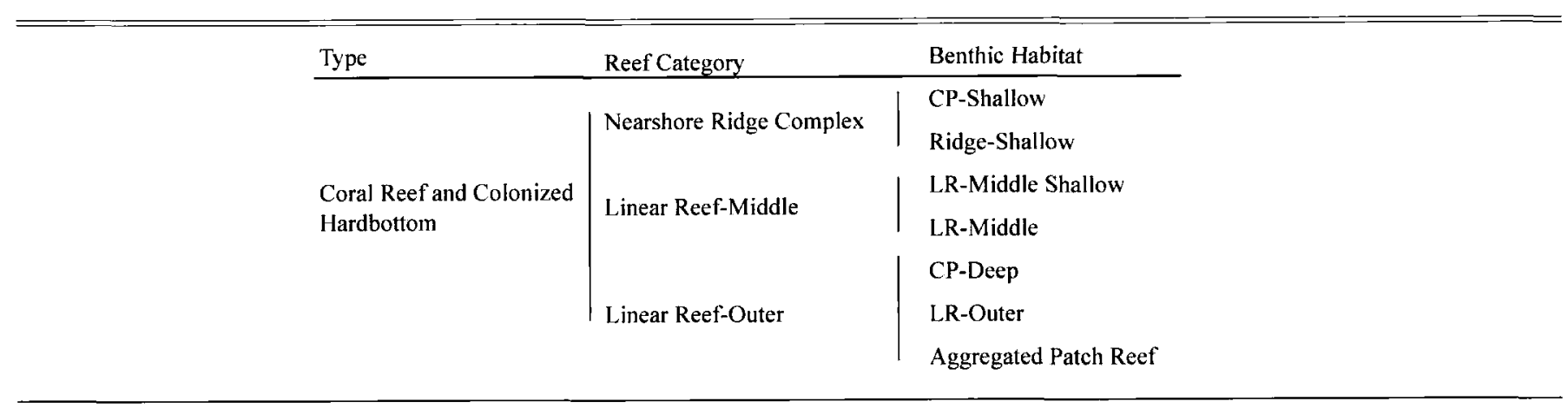

photography, ground-truthing, and expert knowledge, allowed for the characterization of benthic habitats throughout the study area at a 1:6,000 scale and a minimum mapping unit of one acre. These maps had an overall accuracy of $90 \%$ (Walker, Riegl, and Dodge, 2008).

Fish survey site characterizations were defined in two tiers: (1) by their general reef location, and (2) by the appropriate benthic habitat map classification (Table 1). The general reef location categories were Nearshore Ridge Complex (NRC), Middle Reef (MR), and Outer Reef (OR). The benthic habitat classifications used were: Colonized Pavement (CP)-Shallow, Ridge-Shallow, Linear Reef (LR)-Middle Shallow, LR-Middle, CP-Deep, LR-Outer, and Aggregated Patch Reef (Walker, Riegl, and Dodge, 2008).

\section{Data Analysis}

Analysis of variance (ANOVA) was used to examine data for differences in abundance and species richness (i.e., the number of species recorded per count). Abundance data (x) were log transformed using the formula $\log _{10}(x+1)$ to homogenize variance. Tukey HSD (Honestly Significant Differences) post-hoc tests were used to determine differences among means when comparing more than two treatments. Linear regression and correlation analysis were performed in Statistica 6.0 (StatSoft, Inc., Tulsa, OK) and the $r^{2}, r$, and $\mathrm{p}$-value were reported for the best-fit linear regression line.

Stepwise multiple regression was used to determine the topographical metrics which best explained the among-survey variance in abundance and species richness. A Durbin-Watson test statistic was calculated to determine if serial correlation existed between factors. Only adjusted $R^{2}$ values were reported.
A non-metric multi-dimensional scaling (MDS) plot with corresponding cluster analysis was constructed using Bray-Curtis similarity indices from abundance data $(\log [x+1]$ transformed). Analysis of similarity (ANOSIM) and similarity percentage (SIMPER) tests were used to examine the relationship of reef fish assemblages among the different reef categories and benthic habitats (PRIMER v6).

\section{RESULTS}

The 346 point-count reef fish surveys (data from Ferro, Jordan, and Spieler, 2005) analyzed in this study yielded 42,911 total fishes from 184 different species and 51 families. ANOVAs of reef fish abundance $\left(\log _{10}[x+1]\right.$ transformed) and species richness among reef categories showed significantly lower values on the Nearshore Ridge Complex than on the Middle and Outer reefs (Table 2). Mean abundance greatly varied among reef categories. Its high variability appeared to limit the significant differences between Middle and Outer reef categories. ANOVA of fish abundance revealed high variability among and within benthic habitats as well. Significantly more individuals were present in the LR-Middle Shallow, LRMiddle, LR-Outer, and Aggregated Patch Reef habitats than were present in the CP-Shallow and Ridge-Shallow habitats $(p<0.05)$. The LR-Middle Shallow habitat also contained significantly more individuals than the CP-Deep habitat $(p<0.05)$ (Table 2$)$.

In general, benthic habitats with the highest mean fish abundances (LR-Middle, LR-Outer, and Aggregated Patch Reef) exhibited correspondingly higher values of topographic metrics (i.e., elevation, surface rugosity, and volume), with the exception of LR-Middle

Table 2. Mean ( + ISE) values and Tukey HSD significance groupings. Different letters indicate significant difference $(p<0.05)$.

\begin{tabular}{|c|c|c|c|c|c|c|c|}
\hline & Abundance & $\begin{array}{l}\text { Species } \\
\text { Richness }\end{array}$ & $Z \min (m)$ & Elevation(m) & Volume $\left(\mathrm{m}^{3}\right)$ & $\begin{array}{l}\text { Surface-rugosity } \\
\text { Index }\end{array}$ & $\begin{array}{l}\text { Linear-rugosity } \\
\text { Index }\end{array}$ \\
\hline Total & $124.02 \pm 6.34$ & $17.25 \pm 0.34$ & $13.57 \pm 0.44$ & $1.15 \pm 0.04$ & $95.24 \pm 3.85$ & $1.010 \pm 0.0008$ & $1.17 \pm 0.01$ \\
\hline $\mathrm{NRC}$ & $73.95 \pm 6.29^{b}$ & $13.16 \pm 0.49^{b}$ & $4.98 \pm 0.12^{c}$ & $0.64 \pm 0.03^{b}$ & $55.12 \pm 2.57^{b}$ & $1.004 \pm 0.0003^{b}$ & $1.15 \pm 0.01^{b}$ \\
\hline Middle & $144.74 \pm 12.57^{\mathrm{a}}$ & $20.71 \pm 0.56^{a}$ & $18.00 \pm 0.47^{\mathrm{b}}$ & $1.53 \pm 0.09^{\mathrm{a}}$ & $120.62 \pm 7.52^{\mathrm{a}}$ & $1.013 \pm 0.0012^{\mathrm{a}}$ & $1.18 \pm 0.01^{\mathrm{abb}}$ \\
\hline Outer & $170.27 \pm 12.55^{\mathrm{a}}$ & $19.94 \pm 0.38^{\mathrm{a}}$ & $20.96 \pm 0.39^{\mathrm{a}}$ & $1.53 \pm 0.08^{\mathrm{a}}$ & $126.91 \pm 7.70^{\mathrm{a}}$ & $1.017 \pm 0.0020^{\mathrm{a}}$ & $1.20 \pm 0.01^{\mathrm{a}}$ \\
\hline CP-Shallow & $56.41 \pm 8.38^{\mathrm{c}}$ & $12.18 \pm 0.95^{b}$ & $5.35 \pm 0.21^{\mathrm{f}}$ & $0.56 \pm 0.06^{\mathrm{c}}$ & $45.57 \pm 3.78^{\mathrm{c}}$ & $1.003 \pm 0.0006^{\mathfrak{c}}$ & $1.14 \pm 0.01^{b}$ \\
\hline Ridge-Shallow & $82.81 \pm 8.35^{\mathfrak{c}}$ & $13.66 \pm 0.56^{b}$ & $4.80 \pm 0.14^{r}$ & $0.67 \pm 0.03^{c}$ & $59.94 \pm 3.26^{c}$ & $1.004 \pm 0.0003^{\mathrm{c}}$ & $1.16 \pm 0.01^{b}$ \\
\hline LR-Middle Shallow & $190.44 \pm 26.76^{a}$ & $20.93 \pm 1.00^{\mathrm{a}}$ & $12.66 \pm 0.22^{\mathrm{e}}$ & $0.96 \pm 0.10^{\mathrm{b}, \mathrm{c}}$ & $83.64 \pm 8.47^{b, c}$ & $1.007 \pm 0.0015^{\mathrm{b}, \mathrm{c}}$ & $1.19 \pm 0.03^{b}$ \\
\hline LR-Middle & $119.55 \pm 11.49^{\mathrm{a} . \mathrm{b}}$ & $20.59 \pm 0.67^{\mathrm{a}}$ & $20.95 \pm 0.15^{b}$ & $1.85 \pm 0.10^{\mathrm{a}}$ & $141.00 \pm 9.55^{\mathrm{a}}$ & $1.016 \pm 0.0015^{\mathrm{a}, \mathrm{b}}$ & $1.17 \pm 0.01^{\mathrm{b}}$ \\
\hline CP-Deep & $100.69 \pm 10.60^{\mathrm{b}, \mathrm{c}}$ & $18.94 \pm 0.71^{\mathrm{a}}$ & $19.95 \pm 0.10^{c}$ & $1.20 \pm 0.1 !^{b}$ & $82.60 \pm 9.68^{c}$ & $1.008 \pm 0.0012^{h, c}$ & $1.14 \pm 0.02^{\mathrm{b}}$ \\
\hline LR-Outer & $184.29 \pm 18.56^{\mathrm{a}, \mathrm{b}}$ & $20.03 \pm 0.61^{\mathrm{a}}$ & $17.79 \pm 0.29^{d}$ & $1.62 \pm 0.13^{a}$ & $151.79 \pm 13.44^{\mathrm{a}}$ & $1.018 \pm 0.0032^{\mathrm{a}}$ & $1.17 \pm 0.02^{b}$ \\
\hline Agg. Patch Reef & $211.85 \pm 28.72^{\mathrm{a}, \mathrm{b}}$ & $20.74 \pm 0.65^{a}$ & $27.31 \pm 0.25^{\mathrm{a}}$ & $1.69 \pm 0.13^{\mathrm{a}}$ & $126.17 \pm 10.14^{\mathrm{a}, \mathrm{b}}$ & $1.023 \pm 0.0042^{\mathrm{a}}$ & $1.30 \pm 0.03^{a}$ \\
\hline
\end{tabular}


Table 3. Coefficient of determination $\left(r^{2}\right)$ values for regression of fish abundance and lidar metrics. Bold $=$ significant correlation $p<0.05$.

Shallow (Table 2). Likewise, the benthic habitats with the lowest abundances (CP-Shallow and Ridge-Shallow) had the lowest values of elevation, surface rugosity, and volume.

Species richness demonstrated more homogeneity among benthic habitats than fish abundance (Table 2). Both CP-Shallow and RidgeShallow habitats, which did not significantly differ from one another, contained significantly fewer species than all other habitats $(\mathrm{p}<$ 0.05) (Table 2).

Multi-dimensional scaling (MDS) showed fairly distinct clusters when using benthic habitats as factors (Figure 4). Examination of ANOSIM R-statistics confirmed the groupings. The CP-Shallow and Ridge-Shallow sites separated from the LR-Middle Shallow, LR-Middle, CP-Deep, LR-Outer, and Aggregated Patch Reef sites in a cluster analysis exhibiting only $24 \%$ similarity between the two groups. Almost $100 \%$ of the deeper habitat surveys were contained in one cluster group. The wide scattering within the grouping comprised of CP-Shallow and Ridge-Shallow habitats and high stress $(0.21)$ in the MDS plot indicated highly variable assemblages. The other grouping, which was almost exclusively comprised of deeper habitats, was also more compact, indicating less variable assem- blages in the deeper habitats.

Linear regressions of total reef fish abundance and species richness (i.e., all surveys combined) with topographic metrics showed weak but significant, positive relationships. For total abundance, the relationships with lidar metrics were weaker than with the in situ linear rugosity metric. Elevation $\left(r^{2}=0.16\right)$, volume $\left(r^{2}=0.16\right)$, and surface rugosity $\left(r^{2}=0.19\right)$ were lower than linear rugosity $\left(r^{2}\right.$ $=0.30$ ) (Table 3). Yet, for total species richness the relationship to lidar metrics (elevation $\left[\mathrm{r}^{2}=0.22\right]$, volume $\left[\mathrm{r}^{2}=0.17\right]$, and surface rugosity $\left[\mathrm{r}^{2}=0.11\right]$ ) was similar to the in situ metric (linear rugosity $\left[r^{2}=0.18\right]$ ) (Table 4). Despite considerable variability in total fish abundance, species richness, and topographic metrics, the data reflected significant positive linear correlations (Tables 3 and 4). However, these relationships did not persist when split into finer benthic habitat categorization, where abundance and species richness did not significantly correlate to the lidar metrics in many of the benthic habitats. For example, all lidar topographic metrics had their respectively strongest correlation to abundance in the LRMiddle Shallow, but no significant relationships were found in LRMiddle, CP-Deep, and Aggregated Patch Reef habitats (Table 3).

Table 4. Coefficient of determination $\left(r^{2}\right)$ values for regression of fish species richness and lidar metrics. Bold $=$ significant correlation $p<0.05$. 


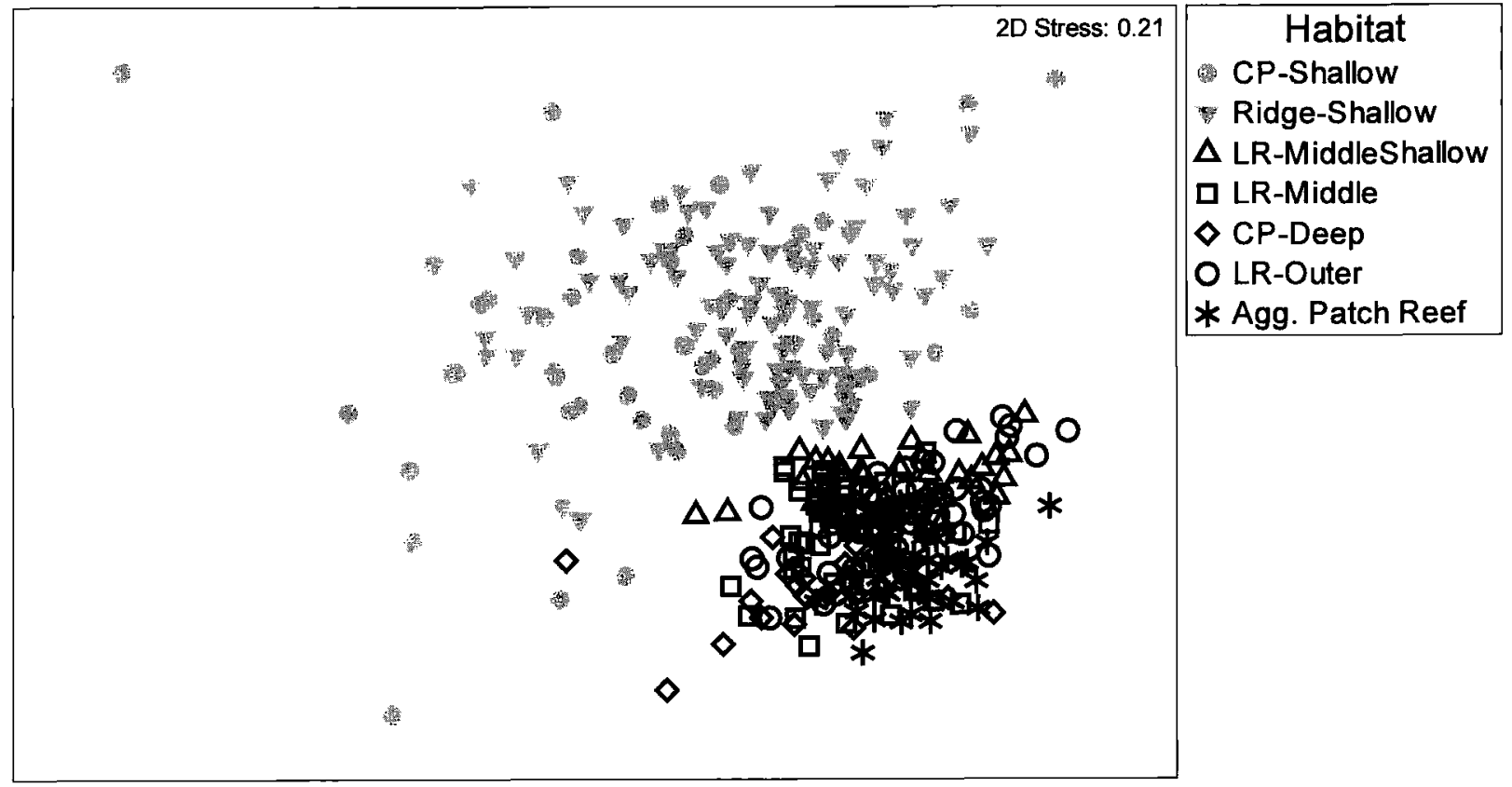

Figure 4. MDS plot using Bray-Curtis similarity indices of reef fish survey data classified by benthic habitat (defined by the survey location from GIS analysis). Solid symbols represent habitats comprising the Nearshore Ridge Complex. LR $=$ Linear Reef; $\mathrm{CP}=\mathrm{Colonized}$ Pavement.

All linear regressions for reef fish abundance and species richness with linear rugosity among reef categories and benthic habitats revealed significant correlation $(\mathrm{p}<0.05)$ except for species richness on the LR-Middle and Aggregated Patch Reef (Table 4). Abundance variability was best explained by linear rugosity in the offshore habitats, with CP-Deep $\left(r^{2}=0.52 ; p<0.05\right)$ and LR-Outer $\left(r^{2}=0.53\right.$; $p<0.05$ ) being the strongest correlate. Linear rugosity appeared to have less influence on abundance variability in the nearshore habitats (CP-Shallow $\left[\mathrm{r}^{2}=0.09\right]$ and Ridge-Shallow $\left[\mathrm{r}^{2}=0.11\right]$; $\mathrm{p}<0.05$ ) (Table 3 ). In contrast, linear rugosity exhibited the strongest relationship with species richness in CP-Shallow $\left(r^{2}=0.38 ; p<0.05\right)$ and Ridge-Shallow $\left(r^{2}=0.25 ; p<0.05\right)$, with a weaker relationship in the offshore habitats (CP-Deep $\left[\mathrm{r}^{2}=0.22\right]$ and LR-Outer $\left[\mathrm{r}^{2}=0.21\right]$; $\mathrm{p}<0.05$ ) (Table 4).

Total species richness (all surveys combined) most strongly correlated with depth $\left(r^{2}=0.27\right)$ (Table 4 ); however, this relationship broke down when the data were categorized into reef categories and benthic habitats. All but two habitats (CP-Shallow and LRMiddle Shallow) lacked significant correlation with depth. This was not surprising because depth was a main criterion for defining the different reef categories and benthic habitats (Walker, Riegl, and Dodge, 2008). Thus, the variance of depths within habitats was very low, reducing the probability of detecting depth correlation on the individual benthic habitat populations.

The lidar metrics showed a strong linear relationship to one another. Elevation strongly correlated with volume $\left(r^{2}=0.81\right)$ and surface rugosity $\left(r^{2}=0.65\right)$; volume correlated with surface rugosity $\left(\mathrm{r}^{2}=0.50\right)$. Surprisingly, linear rugosity failed to strongly correlate with any of the lidar metrics (depth $\left[\mathrm{r}^{2}=0.05\right]$, elevation $\left[\mathrm{r}^{2}=0.10\right]$, surface rugosity $\left[r^{2}=0.19\right]$, or volume $\left[r^{2}=0.07\right]$; all $p<0.0001$ ).

Stepwise multiple regression analysis of four lidar metrics (i.e., depth, volume, elevation, and surface rugosity) indicated significant influence on fish abundance variability. A Durbin-Watson test did not detect the presence of serial correlation in the model $(\mathrm{d}=1.60)$. Of the metrics used, two exhibited a significant influence on total fish abundance among survey sites (adjusted $\mathrm{R}^{2}=0.1842, \mathrm{p}<0.0001$ ). The first step of the multiple regression analysis indicated elevation accounted for $14.48 \%$ of among-site variance in abundance, with depth accounting for an additional $2.5 \%$ of the variance in the second step. The third step of the analysis showed that volume significantly explained an additional $1 \%$ of the variance. However, upon inclusion of volume into the model, elevation no longer exhibited a significant beta value; suggesting volume and elevation are correlated. The relatively low Durbin-Watson statistic generated by analyzing the residuals likely reflected the strong relationship between volume and elevation $\left(r^{2}=0.8120, p<0.0001\right)$. Because of this relationship, the analysis was re-run without elevation (i.e., using volume, depth, and surface rugosity only). Two metrics were found to significantly explain the variance in abundance among sites (adjusted $R^{2}=$ $0.1833, p<0.0001$ ). Results of this stepwise regression indicated volume explained $13.93 \%$ of the abundance variance while depth explained an additional $4.4 \%$. Stepwise multiple regression analysis of the four lidar metrics indicated significant influence on total fish species richness. A Durbin-Watson test did not detect the presence of serial correlation in the model $(\mathrm{d}=1.95)$. Of the metrics used, two exhibited a significant influence on fish species richness (adjusted $\mathbf{R}^{2}$ $=0.3024, \mathrm{p}<0.0001$ ). Depth explained $26.86 \%$ of the among-site variance in species richness, with an additional $3.38 \%$ explained by elevation.

Because fishes are mobile, with different species exhibiting varying home ranges, population data are inherently variable, especially when using visual census. Variability among point-count 
surveys was substantially higher for fish abundance (coefficient of variation $[\mathrm{CV}]=0.95)$ than for species richness $(\mathrm{CV}=0.36)$. Due to the high amount of variability in abundance data, detecting significant correlation with lidar metrics proved difficult even though relationships that explain the variation may exist. In general, the lidar metrics appeared to better correlate with species richness data than with abundance data despite the strong linear relationship of species richness with abundance $\left(\log _{10}[x+1]\right.$ transformed) (r2 $=0.5318, \mathrm{p}<0.0001$ ).

\section{DISCUSSION}

\section{Topographic complexity - reef fish relationship}

Reef fish distributions in southeastern Florida appear to be influenced by topographic complexity. Both reef category and benthic habitat analyses showed similar patterns in which areas of lower topographic complexity exhibited lower reef fish abundance and species richness (Table 2). However, the relationships were complex. In general, reef fish abundance and species richness exhibited a weak but significant, positive correlation with in situ and lidar topographic metrics. The strength and significance of the relationship varied among the three tiers of analyses (i.e., total, reef category, and benthic habitat) and the topographic metrics analyzed (Tables 3 and 4 ).

It is important to analyze the data at the finest habitat categorization possible to best understand the relationships with associated fish assemblages, especially for predictive modeling (Pittman, Costa, and Battista, 2009). Kuffner et al. (2007) stated many previous studies that found correlations between reef fish assemblage attributes (i.e., abundance and/or species richness) and rugosity spanned multiple habitats and/or depths (Chabanet et al., 1997; Friedlander et al., 2003; Gratwicke and Speight, 2005; Luckhurst and Luckhurst, 1978). Despite general agreement between these studies, their results may have been confounded by the inclusion of multiple habitat types (e.g., sand, seagrass, etc.) in the analyses.

The seascape site characterization in our study revealed that the relationships between topographic metrics and fish assemblages varied among benthic habitats. Linear regressions by benthic habitat showed that linear rugosity better correlated to species richness in the Nearshore Ridge Complex habitats (i.e., CP-Shallow and RidgeShallow), but the relationship appeared less evident in the offshore reef habitats. Conversely, linear rugosity exhibited a stronger relationship to abundance in the offshore reef habitats, while the relationship was not significant in benthic habitats associated with the Nearshore Ridge Complex. Our findings are supported by Gratwicke and Speight (2005a and 2005b), who found that rugosity affected species richness but not abundance of shallow water Caribbean reef fish assemblages. However, they did not investigate this relationship in deeper habitats $(>10 \mathrm{~m})$.

The MDS plot showed a distinction as well, having several highly variable clusters associated with the Nearshore Ridge Complex habitats and a more cohesive (i.e., less variable) cluster associated with the offshore reef habitats (Figure 4). These results differed from previously published analyses of these data which found that abundance and species richness significantly differed between all three reef tracts (Inner, Middle, and Outer) (Ferro, Jordan, and Spieler, 2005). This discrepancy was due to misclassification of survey sites, as spatial analysis indicated that many of the sites initially classified as Middle Reef actually plotted on the Nearshore
Ridge Complex, shoreward of the Inner Reef. The erroneous inclusion of nearshore sites in the Middle Reef data reduced the Middle Reef mean abundance and species richness values resulting in significant differences among all three reefs. These errors were evident in their MDS plot (Figure 22, Ferro, Jordan, and Spieler, 2005), showing a high dispersal of Middle Reef sites among the Inner Reef sites. The analyses presented herein used an improved benthic habitat classification scheme, resulting in a more accurate site characterization.

The weak linear relationships between reef fish assemblage parameters and topographic complexity metrics suggest that topographic complexity is not the only limiting factor of reef fish abundance and species richness. Many factors can significantly influence ecological processes and, according to Liebig's Law of the Minimum, the most limiting factors in a correlation will have the strongest relationship (Liebig, 1840). This law encompasses virtually all ecological processes (Huston, 2002). Further, Huston (2002) argued that when a limiting factor is measured, a high correlation between that factor and the process is expected. Yet this factor may be limiting only in specific circumstances; the presence of additional limiting factors then weakens the relationship between the process and the variable under examination. Because the fish abundancetopographic complexity relationship was not strong in this study, Liebig's Law of the Minimum suggests that other factors likely play an important role along with topographic complexity in determining the distribution of reef fish in South Florida.

Fish populations vary on several spatio-temporal scales (Sale, 1991b). Ecological processes including variable replenishment and density-dependent interactions act together to regulate population size, ultimately controlling when and where fishes will be present in a given area (Doherty, 2002; Hixon and Webster, 2002). Since these processes act as the primary drivers for fish assemblage formation and regulation, any additional factors thought to impact population variance (such as topographic complexity) may be overshadowed by the major contributors. Further, replenishment to a given area is regarded as highly variable process, causing inherently variable populations (Doherty and Williams, 1988). The assemblage parameters investigated herein (i.e., abundance and species richness), while useful for resource management and ecological study, include variability for all species. Such variability almost certainly weakens the relationship of fish abundance with secondary influences like topographic complexity.

Despite significance, regression of linear rugosity versus lidar topographic metrics were very weak (elevation $\left[\mathrm{r}^{2}=0.09\right]$, volume $\left[\mathrm{r}^{2}=0.07\right]$, and surface rugosity $\left.\left[\mathrm{r}^{2}=0.16\right]\right)$ compared to previous studies (e.g., $\mathrm{r}^{2}=0.39$ in Kuffner et al. 2007 and $\mathrm{r}^{2}=0.33(100 \mathrm{~m}$ scale) in Pittman, Costa, and Battista, 2009). This suggests that either spatial location errors critical to the determination of the topographic parameters obfuscated the relationships or that bathymetric resolution limited the ability to detect topographic complexity at the operational scale appropriate to fishes. Quality control efforts maximized spatial location accuracy by eliminating $13 \%(81)$ of the surveys due to errant GPS locations. Thus, the probability that spatial errors represented the main source of the high variation in the data appears unlikely. Moreover, unavoidable scaling issues regarding measurement and operational scales also provided a likely source of data variation.

Measurement scale is the scale at which a measurement can be reliably used (Lam and Quattrochi, 1992). The measurement scale for the lidar metrics was dependent upon bathymetric resolution (i.e., the density of depth samples per area). Bathymetric resolution 
constitutes a critical component of the lidar topographic complexity analysis and the difference in calculations of topographic variables can be pronounced between bathymetric surveys of different depth-sample densities. The bathymetric resolution in this study was $4 \mathrm{~m}$. About 12 depth-sample points within each fish survey were used to model the seafloor topographic features. As a result, calculations from these data may not have adequately measured the seafloor complexity within the fish surveys at the precision necessary to capture the relationship.

Operational scale, the scale at which a process operates, is also important because processes operating at one scale may not be evident at other scales (Bian, 1997; Cao and Lam, 1997). Differentsized and -aged fishes may respond to topographic complexity at varying operational scales (Grober-Dunsmore, 2005; Kuffner et al., 2007; Pittman et al., 2007). For example, Purkis, Graham, and Riegl (2008) showed that relationships of fish abundance and benthic rugosity change among size guilds at different scales. In their study, the abundance of $<20 \mathrm{~cm}$ fishes exhibited the strongest relationships to benthic rugosity at the finest resolution scales $(4 \mathrm{~m} \mathrm{kernel})$. The $21-40 \mathrm{~cm}$ fishes had a stronger relationship at a larger scale $(20 \mathrm{~m}$ kemel) while the $41-60 \mathrm{~cm}$ fishes had the strongest relationship at the largest scale ( $40 \mathrm{~m}$ kernel). Our point-count fish surveys did not account for detailed size class information, thus operational scale relationships were unattainable and may have contributed to data variability.

Furthermore, Ferro, Jordan, and Spieler (2005) observed a noticeable absence of large, legal-sized groupers (Serranidae) and snappers (Lutjanidae) in Broward County, FL, finding only two legal-sized groupers in 667 surveys. Broward County averaged 0.57 $(n=667)$ groupers per survey compared to $2.02(n=47)$ on similar habitats in the Upper Florida Keys (Dixie Shoals) (Banks et al., 2008). Similar to Pittman, Costa, and Battista (2009), the reduced abundance of large piscivores in the Broward system likely affected the results of this study. Piscivory likely plays a strong role in shaping reef fish assemblages (Hixon and Menge, 1991), especially in highly rugose areas where fish could avoid predation more effectively, thereby increasing relative fish abundance in areas with high rugosity. Furthermore, groupers and other large fishes utilize reef structure and are more likely to associate with increased reef topographic complexity (Jaap, 1984; Kuffner et al., 2007).

Not much is known regarding the effects of these scaling issues and how they relate to the analyses of reef fish data. Our habitat analysis elucidated previously unobserved changes in the assemblage-topography relationship by better characterization of the survey sites. Similar results may be obtained in studies designed to test this relationship at different spatial scales. The spatial scale used in the current study $\left(\sim 176 \mathrm{~m}^{2}\right)$ was within the recommended range of scales from other studies (Grober-Dunsmore, 2005; Kuffiner et al., 2007); however, these recommendations arose from studies assessing the relationship of fish to reef parameters using similar pointcount methodology. Because the recommended spatial scales in these studies closely matched those of which their survey data were recorded (point count), caution must be taken to ensure their results were not artifacts of the sampling methodology. In other words, fish survey techniques measuring an assemblage on a different spatial scale might yield different recommendations. This is clearly an area in need of more investigation.

\section{Lidar topographic complexity metric evaluation}

It proved difficult to determine which lidar metric best captured the relationship between reef fish assemblages and topographic complexity. Elevation appeared to be a good metric because areas with high reef elevations are known to have higher fish abundance (Kellison and Sedberry, 1998; Rilov and Benayahu, 2002) and it contributed to the best correlation in the total species richness multiple regression. Nevertheless, it is a limited metric because it does not account for surface variations within the survey area. Surface rugosity seemed to be a useful metric because it applies the linear-rugosity measurement to the entire survey surface area, thereby accounting for variations in the surveys that elevation does not, yet it did not contribute in any of the multiple regression analyses. Further, surface rugosity can be biased by extreme elevations. For example, when elevation is low , surface rugosity must be low; higher elevations allow for much more variation to be introduced into the surface-rugosity calculation. Yet, when elevation is extremely high, surface rugosity decreases because the extreme difference in elevation creates a flatter surface. Stepwise multiple regression indicated volume represented the best lidar metric because it exhibited the strongest relationship to fish abundance. Although not a true volume measurement because it does not detect overhangs or reef porosity, volume represents a combination of the other two metrics, surface rugosity and elevation. Volume accounts for surface variations and differences in elevation, unlike the other metrics. All of the examined metrics, however, require little effort to calculate, and should be considered in future studies.

\section{CONCLUSIONS}

Lidar-measured topographic complexity may be a useful metric for reef fish distributional models. However, other factors likely exhibit stronger controls on the population and weak statistical relationships between lidar metrics and fish assemblage parameters may produce weak predictions. Such predictive models would have many scientific and management applications including: viewing data trends across the seascape, estimating and making statistical comparisons of fish stocks, and planning for future designation of marine protected areas. A better understanding of the appropriate scales to use (e.g., spatial, measurement, and operational), the dynamics of the reef fish-topographic complexity relationship, and how other ecological factors influence reef fish assemblages are needed to accurately model their distributions.

\section{ACKNOWLEDGEMENTS}

We thank Fleur Ferro and many graduate student volunteers for collecting the original fish survey data and Bernhard Riegl and Sam Purkis for their insightful comments on this manuscript. We are grateful to Richard Dodge and David Gilliam for supporting this research and to the anonymous reviewers for their helpful insights and suggestions. This manuscript is a result of research partially funded by the National Oceanic and Atmospheric Administration Coastal Ocean Program under award NA03NOS4260046 to Nova Southeastern University for the National Coral Reef Institute (NCRI). This is NCRI contribution \#100.

\section{LITERATURE CITED}

Appeldoorn, R.S.; Recksiek, C.W.; Hill, R.L.; Pagan, F.E., and Dennis, G.D., 1997. Marine protected areas and reef fish movements: the role of habitat in controlling ontogenetic migration. Proceedings of the $8^{\text {th }}$ International Coral Reef Symposium (Panama), 2, pp. 1917-1922.

Banks, K.; Riegl, B.; Richards, V.P.; Walker, B.K.; Helmle, K.P.; Jordan, 
L.K.B.; Phipps, J.; Shivji, M.S.; Spieler, R.E.; and Dodge, R.E., 2008. The reef tract of continental southeast Florida (Miami-Dade, Broward and Palm Beach Counties, USA). In: Riegl, B.M. and Dodge, R.E. (eds.), Coral Reefs of the USA. Netherlands: Springer, pp. 175-220.

Banks, K.; Riegl, B.; Shinn, E.; Piller, W., and Dodge, R., 2007. Geomorphology of the southeast Florida continental reef tract (MiamiDade, Broward, and Palm Beach Counties, USA). Coral Reefs, 26, 617633.

Bell, S.S.; McCoy, E.D., and Mushinsky, H.R., 1991. Habitat structure: the physical arrangement of objects in space. New York: Chapman and Hall, 426p.

Bian, L., 1997. Multiscale nature of spatial data in scaling up environmental models. In: Quattrochhi, D.A. and Goodchild, M.F. (eds.), Scale in remote sensing and GIS. Boca Raton, FL: CRC press, pp. 13-26.

Bohnsack, J.A. and Bannerot, S.P., 1986. A stationary visual technique for quantitatively assessing community structure of coral reef fishes. NOAA Technical Report NMFS, 41, pp. 1-15.

Brock, J.C.; Wright, C.W.; Clayton, T.D., and Nayegandhi, A., 2004. Lidar optical rugosity of coral reefs in Biscayne National Park, Florida. Coral Reefs, 23(1), 48-59.

Cao, C. and Lam, N.S., 1997. Understanding the scale and resolution effects in remote sensing. In: Quattrochhi, D.A. and Goodchild, M.F. (eds.), Scale in remote sensing and GIS. Boca Raton, FL: CRC press, pp. 57-72.

Chabanet, P.; Ralambondrainy, H.; Amanieu, M.; Faure, G., and Galzin, R., 1997. Relationships between coral reef substrata and fish. Coral Reefs, 16, 93-102.

Doherty, P.J. and Williams, D. McB., 1988. The replenishment of coral reef fish populations. Oceanography and Marine Biology: an Annual Review, $26,487-551$.

Doherty, P.J., 2002. Variable replenishment and the dynamics of reef fish populations. In Sale, P.F. (ed.), Coral reef fishes: dynamics and diversity in a complex ecosystem. San Diego: Academic Press, pp. 327-355.

Ferro, F.; Jordan, L.K.B., and Spieler, R.E., 2005. The marine fishes of Broward County, FL: final report of 1998-2002 survey results. NOAA Technical Memorandum NMFS-SEFSC-532, 73p.

Finkl, C.W.; Benedet, L., and Andrews, J.L., 2005. Interpretation of seabed geomorphology based on spatial analysis of high-density airborne laser bathymetry. Journal of Coastal Research, 21(3), 510-514.

Friedlander, A.M. and Parrish, J.D., 1998. Habitat characteristics affecting fish assemblages on a Hawaiian coral reef. Journal of Experimental Marine Biology and Ecology, 224(1), 1-30.

Friedlander, A.M.; Brown, E.K.; Jokiel, P.L.; Smith, W.R., and Rodgers, K.S., 2003. Effects of habitat, wave exposure, and marine protected area status on coral reef fish assemblages in the Hawaiian archipelago. Coral Reefs, 22, 291-305.

Garcia Charton, J.A. and Perez Ruzafa A., 1998. Correlation between habitat structure and a rocky reef fish assemblage in the southwest Mediterranean. Marine Ecology, 19, 111-128.

Gratwicke, B. and Speight, M.R., 2005a. Effects of habitat complexity on Caribbean marine fish assemblages. Marine Ecology Progress Series, 292, 301-310.

Gratwicke, B. and Speight, M.R., 2005b. The relationship between fish species richness, abundance and habitat complexity in a range of shallow tropical marine habitats. Journal of Fish Biology, 66, 650-667.

Green, A.L., 1996. Spatial, temporal and ontogenetic patterns of habitat use by coral reef fishes (Family Labridae). Marine Ecology Progress Series, $133,1-11$.

Grober-Dunsmore, R., 2005. Applying terrestrial landscape ecology principles to the design and management of marine protected areas in coral reef ecosystems. Gainesville, FL: University of Florida, Ph.D. dissertation, 164p.

Hixon, M.A. and Beets, J.P., 1989. Shelter characteristics and Caribbean fish assemblages: experiments with artificial reefs. Bulletin of Marine Science, 44, 666-680.

Hixon, M.A. and Menge, B.A., 1991. Species diversity: prey refuges modify the interactive effects of predation and competition. Theoretical Population Biology, 39, 178-200.
Hixon, M.A. and Webster, M.S., 2002. Density dependence in reef fishes: coral-reef populations as model systems. In: Sale, P.F. (ed.), Coral Reef Fishes: Dynamics and Diversity in a Complex Ecosystem. San Diego: Academic Press, pp. 303-325.

Hobson, R.D., 1972. Surface roughness in topography: quantitative approach. In: Chorley, R.J. (ed.), Spatial analysis in geomorphology. London: Methuen and Co., Ltd., pp. 221-245.

Huston, M.A., 2002. Introductory essay: critical issues for improving predictions. In: Scott, M.J.; Heglund, P.J., and Morrison, M.L. (eds.), Predicting species occurrences: issues of accuracy and scale. Washington: Island Press, pp. 7-21.

Jaap, W.C., 1984. The ecology of the South Florida coral reefs: a community profile. Minerals Management Service MMS 84-0038. 138p.

Jenness, J.S., 2004. Calculating landscape surface area from digital elevation models. Wildlife Society Bulletin, 32(3), 829-839.

Johnson, M.P.; Frost, N.J.; Mosley, M.W.J.; Roberts, M.F., and Hawkins, S.J., 2003. The area-independent effects of habitat complexity on biodiversity vary between regions. Ecology Letters, 6, 126-132.

Jordan, L.K.B.; Gilliam, D.S., and Spieler, R.E., 2005. Reef fish assemblage structure affected by small-scale size and spatial variations of artificial patch reefs. Journal of Experimental Marine Biology and Ecology, 326, 170-186.

Kellison, G.T. and Sedberry, G.R., 1998. The effects of artificial reef vertical profile and hole diameter on fishes off South Carolina. Bulletin of Marine Science, 62, 763-780.

Kuffner, I.B.; Brock, J.C.; Grober-Dunsmore, R.; Bonito, V.E.; Hickey, T.D., and Wright, C.W., 2007. Relationships between reef fish communities and remotely sensed rugosity measurements in Biscayne National Park, Florida, USA. Environmental Biology of Fishes, 78, 71-82.

Lam, N.S. and Quattrochi, D.A., 1992. On the issues of scale, resolution, and fractal analysis in the mapping sciences. The Professional Geographer, 44, 88-98.

Liebig, J., 1840. Chemistry and its application to agriculture and physiology. London: Taylor and Walton, 407p.

Luckhurst, B.E. and Luckhurst, K., 1978. Analysis of substrate variables on coral reef fish communities. Marine Biology, 49, 317-323.

MacArthur, R.H. and MacArthur, J.W., 1961. On bird species diversity. Ecology, 42, 594-598.

McClanahan, T.R., 1994. Kenyan coral reef lagoon fish: effects of fishing, substrate complexity and sea urchins. Coral Reefs, 13, 231-241.

McCormick, M.I., 1994. Comparison of field methods for measuring surface topography and their associations with a tropical reef fish assemblage. Marine Ecology Progress Series, 112, 87-96.

McCoy, E.D. and Bell, S.S., 1991. Habitat structure: the evolution and diversification of a complex topic. In: Bell, S.S.; McCoy, E.D., and Mushinsky, H.R. (eds.), Habitat structure: the physical arrangement of objects in space. New York: Chapman and Hall, p. 3-27.

Petren, K. and Case, T.J., 1998. Habitat structure determines competition intensity and invasion success in gecko lizards. Proceedings of the National Academy of Sciences of the USA, 95, pp. 11739-11744.

Petrie, G., 1990. Modeling, interpolation and contouring procedures. In: Petrie, G. and Kennie, T. J. M. (eds.) Terrain modeling in surveying and civil engineering. Caithness, Scotland: Whittles Publishing Services and Thomas Telford Ltd., 112-127.

Pittman, S.J.; Christensen, J.D.; Caldow, C.; Menza, C., and Monaco, M.E., 2007. Predictive mapping of fish species richness across shallow-water seascapes in the Caribbean. Ecological Modelling, 204, 9-21.

Pittman, S.J.; Costa, B.M., and Battista, T.A., 2009. Using lidar bathymetry and boosted regression trees to predict the diversity and abundance of fish and corals. Journal of Coastal Research, SI(53), 27-38.

Putman, R.J. and Wratten, S.D., 1984. Principles of Ecology. London: Chapman and Hall, 388p.

Purkis, S.J.; Graham, N.A.J., and Riegl, B.M., 2008. Predictability of reef fish diversity and abundance using remote sensing data in Diego Garcia (Chagos Archipelago). Coral Reefs, 27, 167-178.

Recksiek, C.W.; Murphy, B.R.; Appeldoorn, R.S., and Lindeman, K.C., 2001. Integrating fish fauna and habitat assessments: A fundamental step in 
developing fishery reserve design criteria. Proceedings - Gulf Caribbean Fisheries Institute, 52, 654-666.

Rilov, G. and Benayahu, Y., 2002. Rehabilitation of coral reef-fish communities: the importance of artificial-reef relief to recruitment rates. Bulletin of Marine Science, 70, 185-197.

Risk, M.J., 1972. Fish diversity on a coral reef in the Virgin Islands. Atoll Research Bulletin, 153, 1-6.

Sale, P.F., 1991a. Habitat structure and recruitment in coral reef fishes. In: Bell, S.S.; McCoy, E.D., and Mushinsky, H.R. (eds.), Habitat structure: the physical arrangement of objects in space. New York: Chapman and Hall, pp. 197-210.

Sale, P.F., 1991b. The ecology of reef fishes. San Diego: Academic Press, $754 \mathrm{p}$.

Talbot, F.H., 1965. A description of the coral structure of Tutia reef (Tanganyika Territory, East Africa) and its fish fauna. Proceedings of the Zoological Society of London, 145, pp. 431-470.
Talbot, F.H. and Goldman, B., 1972. A preliminary report on the diversity and feeding relationships of reef fishes of One Tree Island, Great Barrier Reef system. Proceedings of the First International Symposium on Corals and Coral Reefs (Mandapam Camp, India), 1, 425-443.

Underwood, A.J. and Chapman, M.G., 1989. Experimental analyses of the influences of topography of the substratum on movements and densities of an intertidal snail, Littorina unifasciata. Journal of Experimental Marine Biology and Ecology, 134, 175-196.

Walker, B.K., 2008. A seascape approach to predicting reef fish distribution. Dania Beach, FL: Nova Southeastern University, Ph.D. thesis, 219p.

Walker, B.K.; Riegl, B., and Dodge, R.E., 2008. Mapping coral reef habitats: a combined technique approach. Journal of Coastal Research, 24(5), 1138-1150.

Wang, K. and Lo, C.P., 1999. An assessment of the accuracy of Triangulated Irregular Networks (TINs) and lattices in ARC/INFO. Transactions in GIS, 3, 161-174. 